\title{
- АКСІОСФЕРА В СИСТЕМІ КЛІЄНТСЬКОГО СЕРВІСУ: ОРГАНІЗАЦІЙНИЙ ДИСКУРС
}

\section{- Плюта Олена Павлівна}

- Кандидат культурології,

ORCID: 0000-0002-8722-4546, e-mail: plyuta-olena@ukr.net,

Київський національний університет культури і мистецтв,

вул. Є. Коновальця, 36, Київ, Україна, 01133

\section{- Для цитування:}

Плюта, О.П. (2021). Аксіосфера в системі клієнтського сервісу: організаційний дискурс. Питання культурології, (38), 166-177. doi: https://doi.org/10.31866/2410-1311.38.2021.245849.

\section{Анотація}

Мета статті — обґрунтувати теоретико-методологічні та науково-практичні аспекти сутності та структури механізму функціонування і розвитку аксіосфери систем клієнтського сервісу. Досягнення поставленої мети зумовило необхідність дослідження, класифікації, експертної оцінки головних визначальних чинників і елементів аксіосфери систем клієнтського сервісу. Методологічною основою став комплекс взаємопов'язаної сукупності різних методів наукового дослідження: аналізу та синтезу — для окреслення теоретичних прикладних засад проблем формування аксіосфери; діалектичного пізнання - для постановки проблеми дослідження, вивчення та деталізації об'єкта дослідження; семантичного аналізу - для визначення сутності основних понять проблемного поля дослідження; спостереження й узагальнення для характеристики сучасного стану підприємств та визначення тенденцій розвитку сфери гостинності; структурно-логічного аналізу 一 для встановлення взаємозв'язків між категоріями досліджуваної проблеми. Методологічним орієнтиром дослідження проблеми стали ключові методологічні підходи - аксіологічний, системний, культурологічний, компетентнісний, синергетичний та ін. Наукова новизна. Розвинуто науковий підхід до визначення структурнозмістового наповнення механізму функціонування і розвитку аксіосфрери систем клієнтського сервісу через розширення суб'єктивного складу, що надає системі ефективного значення. Висновки. Обґрунтовано доцільність використання певного набору формалізованих підходів до формування систем організаційної культури та професійного компетентнісного потенціалу в системах клієнтського сервісу, що, як наслідок, забезпечить додану та ринкову вартість бізнесу підприємств готельно-ресторанної сфери. Брак комплексності та системності у висвітленні питань удосконалення та ефективності систем клієнтського сервісу зумовлює потребу в подальших теоретичних дослідженнях цієї проблеми.

Ключові слова: цінність; аксіологія; аксіосфера; клієнтський сервіс; організаційна (корпоративна) культура; професійна компетенція; готельно-ресторанний бізнес; сфрера гостинності 


\section{- Вступ}

Соціально-культурний сервіс - складна, багатокомпонентна система, завдання якої полягає в забезпеченні населення різноманітними послугами. Невід'ємною частиною соціально-культурного сервісу є сфера гостинності, яка являє собою унікальне соціальне явище - системи клієнтського сервісу. В епоху невизначеності та інтенсифрікації соціальних, інноваційних та інформаційних процесів перед підприємствами сфери гостинності гостро постають проблеми фахового підходу до функціонування систем клієнтського сервісу та досягнення і утримання їх ефеективності і розвитку.

На важливості ролі корпоративної (організаційної) культури у реалізації стратегічних цілей розвитку підприємств зосереджують свою увагу як закордонні, так і українські вчені.

Поняття організаційної культури широко досліджені в закордонному менеджменті такими науковцями, як Г. Хофстеде (Hofstede, 1994), Е. Холл (Hall, 1976), Р. Льюіс (Льюис, 1999), Е. Шейн (Schein, 1999), Т. Пітерс і Р. Уотерман (Питерс \& Уотерман, 1986), К. Камерон та Р. Куінн (Камерон \& Куинн, 2001) та ін. В переважній кількості закордонних вчених організаційна культура як феномен запозичена із американського і європейського менеджменту і насамперед зосереджується на її ролі в підвищенні ефективності діяльності підприємств. Однак слід зазначити неможливість їх повного застосування у вітчизняних практиках через особливі чинники національного менталітету. Серед українських вчених слід виділити таких як Ф. Бутинець (2004), А. Воронкова, М. Баб'як, Е. Коренєв, та І. Мажура, (2006), О. Грішнова і А. Науменко (2010), В Співак (2001) та ін.

Формуванням організаційної (корпоративної) культури на основі аксіологічного (ціннісного) підходу переймалися як закордонні, так і вітчизняні вчені, серед яких Є. Єрошенкова (Ерошенкова, 2016), Г. Ріккерт (1998), М. Рокич (Психологический журнал, 2015), А. Флієр (Флиер, 2016).

Проблема набуття необхідних професійних компетенцій задля ефективності функціонування і розвитку сфери готельно-ресторанного бізнесу стала поштовхом для численних наукових досліджень В. Бланка (Blank, 1982), Р. Бояціз (Boyatzis, 1982), В. Верби та О. Гребешкової (2004), О. Голосова та І. Дрогобицького (Голосов \& Дрогобыцкий, 2006), Н. Дем'янченко (Демьянченко, 2012), О. Дороніної (Доронина, 2010) тощо.

Водночас слід зазначити, що попри багатосторонність теоретико-прикладних досліджень з питань функціонування підприємств сфери гостинності, все ж досі залишаються невирішеними важливі наукові завдання. Зокрема потребує ґрунтовного удосконалення методологія оцінювання впливу нематеріальних чинників на ефективність фрункціонування систем клієнтського сервісу.

\section{- Мета статті}

Мета статті - обґрунтувати теоретико-методологічні та науково-практичні аспекти сутності та структури механізму функціонування і розвитку аксіосфери систем клієнтського сервісу. Досягнення поставленої мети зумовило необхідність дослідження, класифрікації, експертної оцінки головних визначальних чинників і елементів аксіосфери систем клієнтського сервісу. 


\section{- Виклад матеріалу дослідження}

Нині керівники усвідомлюють необхідність нарощування організаційного, соціального, репутаційного та ін. нематеріальних видів капіталу, оскільки їх вплив на конкурентоздатність і ефеектиність роботи перевищує результат від нарощування матеріальних ресурсів і дає тільки довгостроковий ефект. На сьогодні для оздоровлення підприємств «щеплень» звичайним менеджментом, який розрахований на управління в цих умовах недостатньо. Проблеми «мутують», стають більш вразливими, непередбачуваними.

Світ стикається із кризами та новими реаліями, які вимагають нової системи координат - розуміння необхідності комплексного нового мислення з погляду цінності функціонування підприємств готельно-ресторанного бізнесу. Причина відставання якості послуг від аналогічних підприємств в країнах $Є С-$ несформованість прогресивної організаційної культури (поняття «організаційна культура» та «корпоративна культура» розглядаються як тотожні) підприємств, яка має стати рушійною силою позитивних змін в обслуговуванні споживачів.

Проблема фрормування аксіосфрери систем клієнтського сервісу на сьогодні ще більш актуалізується як для бізнес-середовища сфери гостинності, так і для науковців через постійне зростання значущості таких показників ефективності, як нематеріальні активи, в основі яких компетентність та цінності. Слід зазначити, що цінності кожного окремого підприємства сфери гостинності ґрунтуються на характері ринку тієї чи іншої країни у певний час. Підвищений дослідницький інтерес до проблеми формування і управління організаційною культурою невипадковий. Ціннісна динаміка у сфері послуг в сучасний період підсилюється зростанням тренду таких чинників: знання (когнітивна цінність); домінантне значення інформації проти інших ресурсів; новації та інновації як цінності нової епохи; феномен віртуалізації, зародження та формування електронної культури (це поняття ще потребує подальшого дослідження і уточнення, однак це явище вже існує); нова гуманітарна технологія - управління організацією через культуру; нове мислення (цінності гармонії та спільного розвитку, взаєморозуміння, толерантність, емпатія тощо. Країни, у яких найбільший відсоток нового мислення мають найвищий індекс щастя. Це Скандинавські країни, Канада, Австралія, Нова Зеландія. В Україні частка населення з новим мисленням, на думку експертів, становить в середньому $5 \%$, а у Скандинавських країнах - більш ніж половина населення).

Проблема дослідження, мета, аналіз наукових джерел та сформульовані завдання визначили методологію і теоретико-практичну основу дослідження. Методологічною основою дослідження став комплекс взаємопов'язаної сукупності різних методів наукового дослідження: аналізу та синтезу - для дослідження теоретичних прикладних засад проблем формування аксіосфери; діалектичного пізнання - для постановки проблеми дослідження, вивчення та деталізації об'єкту дослідження; семантичного аналізу — для визначення сутності основних понять проблемного поля дослідження; спостереження й узагальнення - для характеристики сучасного стану підприємств та визначенні тенденцій розвитку сфери гостинності; структурно-логічного аналізу — для встановлення взаємозв'язків між категоріями досліджуваної проблеми. Методологічним орієн- 
тиром дослідження проблеми стали ключові методологічні підходи - системний, культурологічний, компетентнісний, синергетичний та ін. Важливе місце серед методологічного ряду підходів займає аксіологічний. Висхідними для аксіологічного, в контексті проблеми, є культурологічний, соціокультурний і компетентнісний підходи, які досить ґрунтовно розкриті у дослідженнях Л. Батченко та Л. Гончар (Rusavska et al., 2020).

Культурологічний (ціннісний) підхід - основний метод проєктування особистісно орієнтованої освіти. Культурологічний підхід в освіті - це методологічна орієнтація, яка у своїй філософській основі має аксіологічний (ціннісний) вектор розвитку (Rusavska et al., p. 98).

Соціокультурний підхід утримує вагомі можливості для реалізації суттєвих вимог до системи освіти XXI ст. Він передбачає об'єднання змісту освіти і виховання молоді в цілісний освітній процес на основі єдиної цілі, єдиних соціокультурних цінностей і технологій ефективного навчання. Він забезпечує гармонічність розвитку особистості студента. Він розвиває освіту як відкриту організаційну систему, яка здатна стати важливим єднальним чинником (Rusavska et al., 2020, p. 98).

Компетентнісний підхід є одним із ключових методологічних інструментів модернізації профресійної освіти в країнах Європи. Проєктування освітніх програм згідно з компетентнісним підходом означає відображення в системному і цілісному вигляді результатів освіти. Компетентнісний підхід необхідний, але він повинен бути збалансований підсиленням гуманізації в освітній діяльності закладів вищої освіти (Rusavska et al., 2020, p. 98).

Зміст аксіологічного підходу визначається сутністю аксіології як вчення про цінності. Вивчення аксіології завжди було важливим, але особливої актуалізації ця проблема набула в XXI ст. через зміну у структурах цінностей. В другій половині XIX ст. в системі управління виробничою діяльністю увага до соціальних і соціокультурних параметрів була відносно слабкою. Аксіологія ще не проникла у сфреру організації праці і управління, панував принцип максимізації прибутку через мінімізацію витрат на робочу силу. Тенденція формування нових змістовних концептів цінності ґрунтується на наявності системи аксіологічного знання, надаючи їй багатомірний і поліпарадигмальний характер (Batchenko et al., 2020, р. 43).

Термін аксіологія був введений 1902 року французьким фрілософом П. Лапі (Крайнікова, 2017). Аксіологія як фрілософська дисципліна досліджує природу цінностей, їх місце в реальній дійсності, структуру ціннісного світу, обумовленість соціальними і культурними чинниками. Аксіологія освіти допомогла створити науково обґрунтовані моделі сучасної освіти, спрогнозувати тенденції ії розвитку. В другій половині 80-х років починають формуватися загальні риси педагогічної аксіології (В. Розін (Розин, 1989), П. Щедровицький (Щедровицкий, 1968)).

Категорія цінності - це різнопланові та різнорівневі явища, які логічно пов'язані із поняттями «відносини», «потреба», «корисність», «сенс», «переконання». В бізнесі на практиці ці категорії часто мають суб'єктивний характер. Щоби цінності в організації працювали, їх необхідно формалізувати і ре- 
алізувати в бізнес-процесах. Якщо підприємство фокусує свою діяльність на цінностях, то воно $є$ клієнтоорієнтованим, оскільки ставить клієнта на перше місце.

Ціннісні орієнтації є відносно стійкою і незмінною складовою організаційної (корпоративної) культури в ії базових визначеннях - цілях, пріоритетах, правилах.

Корпоративна культура - це усвідомлення єдиного корпоративного духу, стилю, іміджу, норм і цінностей, переконань, очікувань, ділових принципів, традицій тощо. Тобто це - джерельне нематеріальне середовище організації, яка вибудовує свої «секретні інгредієнти успішності бізнесу». Вона не може бути позитивною або негативною, бо процеси розвитку цього явища динамічні (нестійкі) і під впливом фракторного ряду ознаки позитивної або негативної культури змінюються.

Щоб організаційна культура була результативною необхідно змінити майндсет (mindset) співробітників - звичний склад розуму, свідомість, розуміння і сприйняття цінностей організації, набір переконань тощо.

Для готельно-ресторанного бізнесу організаційна культура - чітке визначення правил гри, фрормалізація і регламентація взаємин, визначене і закріплене ядро цінностей, впровадження принципу корпоративної лояльності. Такий ряд підсилить економічні важелі конкурентоспроможності організації через свою унікальну організаційну культуру. I ця власна унікальна система передаватиметься новим співробітникам як правильне базисне комплексне поняття, яке пов'язує в єдине ціле систему клієнтського сервісу.

При формуванні подібної системи корисним буде скористатися Азбукою організаційної культури за Е. Холлом (Hall, 1976) (АВC), де:

A (artifacts) - артефракти і етикет (поверхневий рівень);

B (behaviors) - стереотипи поведінки (більш глибокий рівень);

C (core morales) - мораль, переконання, спільні цінності (ядро).

За В. Співаком (Спивак, 2001), організаційна культура - це провідний чинник, який визначає специфріку фрірми, особливості взаємодії співробітників, вимоги до працівників і відношення до них.

За Е. Петтігрю (Pettigrew, 1985), організаційна культура - це «корпоративний клей», який «прикріплює м'язи» бізнес-процесів до «кісток» організаційної структури.

Організаційна культура суб'єктів господарювання ринку готельно-ресторанних послуг попри свою особливість і унікальність, фрормується все ж в науково-прикладній площині з дотриманням ключових наукових принципів (аксіологічність, примат співробітництва над конкуренцією, соціальна відповідальність, терпимість до культурних розбіжностей, емпатія та ін.) і певних правил.

У своїх відомих 14 принципах управління Е. Демінг (Деминг, 2007) у восьмому принципі - Корпоративна культура - зазначив наступне: «Організації повинні вивчати і цілеспрямовано формувати свою корпоративну культуру. Важливо створити позитивний настрій для роботи». Ці слова Е. Демінга не тільки правильні, вони і сьогодні на часі. Задоволені співробітники - основний сенс 
організаційної культури. Щасливі співробітники, на думку експертів, підвищують свою продуктивність до $30 \%$.

Принцип клієнтоорієнтованості для сфрери гостинності не повинен бути пустим словом, а має стати ключовим принципом в роботі. Система клієнтського сервісу організації повинна декларувати першим своїм правилом - гість (клі$€ н т)$ наша головна цінність, без гостя (клієнта) наша робота не має сенсу.

Правило друге: в організації працюють правильні люди.

Правило третє: ми - команда.

Правило четверте: ми - лідери в профресії і лідери на ринку.

Тільки інтегрований конструкт із принципів, підходів і правил надасть системі клієнтського сервісу результативного характеру і доданої вартості бізнесу через бренд, репутацію і довіру споживачів.

Організаційна культура - це ціннісно-нормативний простір (аксіосфрера), в якому існує організація у взаємодії із іншими організаційними структурами. В сучасній науці поняття аксіосфера активно вживається в різних контекстах: культурологічному («аксіосфрера культури»), соціальному («аксіосфера суспільства»), особистісному («аксіосфера особистості»), професійному («професійна аксіосфрера»), педагогічному («аксіосфера виховання», «аксіосфрера закладу освіти») тощо.

Враховуючи соціокультурну специфріку сфери гостинності, можна передбачити, що її простір являє собою феномен міжкультурної дифузії, який виходить за межі теоретичного усвідомлення сучасного культурного процесу. Бізнес-культурологічна параметризація сфери гостинності ґрунтується на дискурсах цінності: для клієнтів (гостей) - сервіс, орієнтований на бренд; для співробітників - лідер, якого вибирають; для суспільства - соціально-відповідальна організація (відповідальність юридична, економічна, соціальна, етична, фрілантропічна тощо).

Для досягнення успіху необхідно реалізувати комплексну трансформацію бізнесу і створення аксіосфери культури організації.

Аксіологічний підхід до розв'язання проблеми стійкого розвитку сфери готельно-ресторанного бізнесу повинен утримувати в собі роль аксіосфрери фахівця, його систему ціннісних орієнтацій.

Аксіологічний компонент професійної підготовки відображений в професійних компетенціях. Це - ціннісно-змістова орієнтація, яка практикується як розуміння цінності культури, усвідомлення соціальної значущості майбутньої професії, здатність до співробітництва, толерантність, комунікативність.

Професійна компетентність повинна охоплювати інтелектуальну, соціальну, аксіологічну, етичну та поведінкову складові. Встановлено, що професійні компетенції наполовину щезають приблизно за 2-3 роки і протягом 5-7 років зникають повністю, якщо людина не вчиться, не одержує нові навички і здібності. Завдання кожного співробітника - безперервно вчитися, набувати нових знань, у такий спосіб зберігаючи свою конкурентоздатність на ринку праці (Батченко \& Гончар, 2019).

Знання як елемент компетенцій і ресурс організації набуває все більшого впливу на ефективність процесів, що, зрештою, впливає на якість і рентабельність продукції та послуг та додає їм цінності (Батченко \& Гончар, 2019). 


\section{- Висновки}

Обґрунтовано доцільність використання певного набору формалізованих підходів до фрормування систем організаційної культури та професійного компетентнісного потенціалу клієнтського сервісу, що забезпечить додану та ринкову вартість бізнесу підприємств готельно-ресторанної сфрери. Визначено, що для досягнення успіху необхідно реалізувати комплексу трансформацію бізнесу і створення аксіосфрери культури організації. Аксіологічний підхід до розв'язання проблеми стійкого розвитку сфери готельно-ресторанного бізнесу повинен утримувати в собі роль аксіосфери фахівця, його систему ціннісних орієнтацій. Встановлено, що професійна компетентність повинна охоплювати інтелектуальну, соціальну, аксіологічну, етичну та поведінкову складові. Брак комплексності та системності у висвітленні питань удосконалення та ефективності систем клієнтського сервісу зумовлює потребу в подальших теоретичних дослідженнях цієї проблеми.

\section{- Список використаних джерел}

Батченко, Л. В., \& Гончар, Л. О. (2019). Розвиток професійних компетенцій персоналу як основа економічного зростання. Актуальні проблеми економіки, 11(221), 22-33. https://eco-science.net/archive/2019/APE-11-2019/11.19_topic_ Batchenko\%20L.V,\%20Honchar\%20L.O.pdf

Бутинець, Ф. Ф. (Ред.). (2004). Світовий бізнес. Рута.

Верба, В. А., \& Гребешкова, О.М. (2004). Проблеми ідентифікації компетенцій підприємства. Проблеми науки, (7), 23-28.

Воронкова, А., Баб'як, М., Коренєв, Е., \& Мажура, І. (2006). Корпорація: управління та культура. Вимір.

Голосов, О., \& Дрогобыцкий, И. (2006). Компетенции - это самый тяжелый пласт в разработке стандартов. Прикладная инфоорматика, 4(4), 108-113.

Грішнова, О. А., \& Науменко, А. В. (2010). Корпоративна культура як ресурс забезпечення стратегічної стійкості підприємства. Экономика и управление, 2(22), 33-38.

Деминг, Э. (2007). Выход из кризиса: Новая парадигма управления людьми, системами и процессами. Альпина Бизнес Букс.

Демьянченко, Н. В. (2012). Компетенция персонала в системе менеджмента современной организации. Сфрера услуг: инновации и качество, (5). http://journal.kfrgteu.ru/ files/1/2012_5_12.pdf

Доронина, О. (2010). Компетенции как инструмент менеджмента, ориентированный на практическую деятельность в организации. Консультант, (23), 59-63.

Ерошенкова, Е. И. (2016) Аксиологические ориентиры образовательной реальности: от истоков к современности профессионального образования. Гаудеамус, (4), $9-14$.

Камерон, К., \& Куинн, Р. (2001). Диагностика и изменение организационной культуры. Питер.

Крайнікова, Т. С. (2017). Аксіологія. В Велика українська енциклопедія. https://vue.gov.ua/ Аксіологія

Льюис, Р. Д. (1999). Деловые культуры в международном бизнесе. От столкновения до взаимопонимания. Дело. 
Питерс, Т., \& Уотерман, Р. (1986). В поисках эфффективного управления. Прогресс.

Психологический журнал. (2015, 22 октября). Исследование ценностных ориентаций

М. Рокича. https://psychojournal.ru/tests/479-issledovanie-cennostnyh-orientaciym-rokicha.html

Риккерт, Г. (1998). Науки о природе и науки о культуре. Республика.

Розин, В. М. (1989) Специфика и формирование естественных, технических и гуманитарных наук. Издательство Красноярского универститета.

Спивак, В. А. (2001). Корпоративная культура. Питер.

Флиер, А.Я. (2016) Социодинамика культуры: многообразие возможностей. Культура культуры, (1). http://cult-cult.ru/sociodynamics-of-culture-a-variety-ofpossibilities/

Щедровицкий, Г.П.(1968) Система педагогических исследований (Методологический анализ). http://surl.li/alzho

Batchenko, L., Dielini, M., \& Honchar, L. (2020). A Value-Oriented Polyparadigmal Approach to the Development of Management Education in the Conditions of Transformation Change. Baltic Journal of Economic Studies, 6(5), 42-53. https://doi. org/10.30525/2256-0742/2020-6-5-42-53

Blank, W. E. (1982). Handbook for developing Competency Based Training Programs. Prentice Hall.

Boyatzis, R. E. (1982) The Competent Manager: a Model for Effective Performance. Wiley.

Hall, E. T. (1976). How Cultures Collide. Psychology Today, July, 67-74.

Hofstede, G. (1994). Cultural and Organizaions: Software of the Mind. Harper.

Pettigrew, A. M. (1985). Examining Changes in the Long-Term Context of Culture and Politics. In M. J. Pennings (Ed.), Organizational Strategy and Change (pp. 269-318). JosseyBass.

Rusavska, V., Batchenko, L., Honchar, L., \& Svechkina, A. (2020). Formation of IntegrativeInnovative Educational Model of Training of Managers of Socio-Cultural Activity of Ukraine: Conceptual-Analytical View. Socio-Cultural Management Journal, 3(2), 75-106.

Schein, E. H. (1999). The Corporate Culture Survival Guide. Jossey-Bass.

\section{- References}

Batchenko, L. V., \& Honchar, L. O. (2019). Rozvytok profesiinykh kompetentsii personalu yak osnova ekonomichnoho zrostannia [Development of professional competences of personnel as the basis of economic growth]. Actual Problems of Economics, 11(221), 22-33. https://eco-science.net/archive/2019/APE-11-2019/11.19_topic_ Batchenko\%20L.V,\%20Honchar\%20L.O.pdf [in Ukrainian].

Batchenko, L., Dielini, M., \& Honchar, L. (2020). A Value-Oriented Polyparadigmal Approach to the Development of Management Education in the Conditions of Transformation Change. Baltic Journal of Economic Studies, 6(5), 42-53. https://doi. org/10.30525/2256-0742/2020-6-5-42-53 [in English].

Blank, W. E. (1982). Handbook for developing Competency Based Training Programs. Prentice Hall [in English].

Boyatzis, R. E. (1982) The Competent Manager: a Model for Effective Performance. Wiley [in English]. 
Butynets, F. F. (Ed.). (2004). Svitovyi biznes [World Business]. Ruta [in Ukrainian].

Deming, E. (2007). Vykhod iz krizisa: Novaya paradigma upravleniya lyud'mi, sistemami i protsessami [Overcoming the Crisis: A New Paradigm for Managing People, Systems and Processes]. Al'pina Biznes Buks [in Russian].

Dem'yanchenko, N. V. (2012). Kompetentsiya personala $\vee$ sisteme menedzhmenta sovremennoi organizatsii [Competence of personnel in the system modern management organisation]. Services Sector: Innovation and Quality, (5). http:// journal.kfrgteu.ru/files/1/2012_5_12.pdf [in Russian].

Doronina, O. (2010). Kompetentsii kak instrument menedzhmenta, orientirovannyi na prakticheskuyu deyatel'nost' $v$ organizatsii [Competencies as a management tool focused on practical activities in the organisation]. Konsul'tant, (23), 59-63 [in Russian].

Eroshenkova, E. I. (2016) Aksiologicheskie orientiry obrazovatel'noi real'nosti: ot istokov $\mathrm{k}$ sovremennosti professional'nogo obrazovaniya [Axiological guidelines of educational reality: from the origins to the modernity of vocational education]. Gaudeamus, (4), 9-14 [in Russian].

Flier, A. Ya. (2016) Sotsiodinamika kul'tury: mnogoobrazie vozmozhnostei [Sociodynamics of Culture: Diversity of Opportunities]. Culture of Culture, (1). http://cult-cult.ru/ sociodynamics-of-culture-a-variety-of-possibilities/ [in Russian].

Golosov, O., \& Drogobytskii, I. (2006). Kompetentsii — eto samyi tyazhelyi plast v razrabotke standartov [Competencies are the hardest layer in developing standards]. Journal of Applied Informatics, 4(4), 108-113 [in Russian].

Hall, E. T. (1976). How Cultures Collide. Psychology Today, July, 67-74 [in English].

Hofstede, G. (1994). Cultural and Organizaions: Software of the Mind. Harper [in English].

Hrishnova, O. A., \& Naumenko, A. V. (2010). Korporatyvna kultura yak resurs zabezpechennia stratehichnoi stiikosti pidpryiemstva. [Corporate culture as a resource for ensuring the strategic stability of the enterprise]. Ekonomika $i$ Upravlenie, 2(22), 33-38 [in Ukrainian].

Kameron, K., \& Kuinn, R. (2001). Diagnostika i izmenenie organizatsionnoi kul'tury [Diagnostics and Change of Organisational Culture]. Piter [in Russian].

Krainikova, T. S. (2017). Aksiolohiia [Axiology]. In Velyka Ukrainska Entsyklopediia. https:// vue.gov.ua/Aksiolohiia [in Ukrainian].

Lewis, R. D. (1999). Delovye kul'tury $v$ mezhdunarodnom biznese. Ot stolknoveniya do vzaimoponimaniya [Business Cultures in International Business. From Collision to Mutual Understanding]. Delo [in Russian].

Pettigrew, A. M. (1985). Examining Changes in the Long-Term Context of Culture and Politics. In M. J. Pennings (Ed.), Organisational Strategy and Change (pp. 269-318). JosseyBass [in English].

Piters, T., \& Uoterman, R. (1986). V poiskakh effektivnogo upravleniya [In Search of Effective Management]. Progress [in Russian].

Psikhologicheskii Zhurnal. (2015, October 22). Issledovanie tsennostnykh orientatsii M. Rokicha [Research of Value Orientations by M. Rokich]. https://psychojournal.ru/ tests/479-issledovanie-cennostnyh-orientaciy-m-rokicha.html [in Russian].

Rikkert, G. (1998). Nauki o prirode i nauki o kul'ture [Natural Sciences and Cultural Sciences]. Respublika [in Russian]. 
Rozin, V. M. (1989) Spetsifika i formirovanie estestvennykh, tekhnicheskikh i gumanitarnykh nauk [Specificity and Formation of Natural, Technical and Humanitarian Sciences]. Izdatel'stvo Krasnoyarskogo universtiteta [in Russian].

Rusavska, V., Batchenko, L., Honchar, L., \& Svechkina, A. (2020). Formation of IntegrativeInnovative Educational Model of Training of Managers of Socio-Cultural Activity of Ukraine: Conceptual-Analytical View. Socio-Cultural Management Journal, 3(2), 75-106 [in English].

Schein, E. H. (1999). The Corporate Culture Survival Guide. Jossey-Bass [in English].

Shchedrovitskii, G. P. (1968) Sistema pedagogicheskikh issledovanii (Metodologicheskii analiz) [Pedagogical Research System (Methodological Analysis)]. http://surl.li/alzho [in Russian].

Spivak, V. A. (2001). Korporativnaya kul'tura [Corporate Culture]. Piter [in Russian].

Verba, V. A., \& Hrebeshkova, O. M. (2004). Problemy identyfikatsii kompetentsii pidpryiemstva [Problems of identification of enterprise competencies]. Problems of Science, (7), 23-28 [in Ukrainian].

Voronkova, A., Bab'iak, M., Koreniev, E., \& Mazhura, I. (2006). Korporatsiia: upravlinnia ta kultura [Corporation: Management and Culture]. Vymir [in Ukrainian].

\section{AXIOSPHERE IN THE CUSTOMER SERVICE SYSTEM: ORGANISATIONAL DISCOURSE}

\section{- Olena Pliuta}

- PhD in Cultural Studies,

ORCID: 0000-0002-8722-4546, e-mail: plyuta-olena@ukr.net,

Kyiv National University of Culture and Arts,

Kyiv, Ukraine

\section{Abstract}

The purpose of the article is to substantiate theoretical and methodological, scientific and practical aspects of the essence and structure of the mechanism of functioning and development of the axiosphere of customer service systems. Achieving this goal necessitated research, classification, expert assessment of the main determinants and elements of the axiosphere of customer service systems. The methodological basis of the study is an interrelated set of different methods of scientific research: analysis and synthesis are used to outline the theoretical applied principles of the issues of axiosphere formation; dialectical cognition is applied to identify the problem of research, study and detail research object; semantic analysis is used to determine the essence of the main concepts of the research issues; observation and generalisation are used to characterise the current state of enterprises and determine trends in the development of the hospitality industry; structural and logical analysis is applied to establish relationships between the categories of the issues under study. The key methodological approaches, including axiological, systemic, culturological, competence-based, synergetic, etc. became the methodological guide for studying the issue. Scientific novelty. A scientific approach to determining the structural and semantic content of the mechanism of functioning and development of the axiosphere of 
customer service systems by expanding the subjective composition that gives the system an effective meaning has been developed. Conclusions. The expediency of using a certain set of formalised approaches to the formation of systems of organisational culture and professional competence potential in customer service systems has been justified, which, as a result, will ensure the added and market value of the business of hotel and restaurant enterprises. The lack of complexity and consistency in covering the issues of improvement and efficiency of customer service systems determines the need for further theoretical research on this issue.

Keywords: value; axiology; axiosphere; customer service; organisational (corporate) culture; professional competence; hotel and restaurant business; hospitality sector

\section{АКСИОСФЕРА В СИСТЕМЕ КЛИЕНТСКОГО СЕРВИСА: ОРГАНИЗАЦИОННЫЙ ДИСКУРС}

\section{- Плюта Елена Павловна}

- Кандидат культурологии,

ORCID: 0000-0002-8722-4546, e-mail: plyuta-olena@ukr.net, Киевский национальный университет культуры и искусств, Киев, Украина

\section{Аннотация}

Цель статьи - обоснование теоретико-методологических и научно-практических аспектов относительно сущности и структуры механизма функционирования и развития аксиосферы систем клиентского сервиса. Достижение поставленной цели обусловило необходимость исследования, классификации, экспертной оценки главных определяющих факторов и элементов аксиосферы систем клиентского сервиса. Методологической основой исследования стал комплекс взаимосвязанной совокупности различных методов научного исследования: анализа и синтеза - для исследования теоретических прикладных основ проблем фрормирования аксиосферы; диалектического познания для постановки проблемы исследования, изучения и детализации объекта исследования; семантического анализа - для определения сущности основных понятий проблемного поля исследования; наблюдения и обобщения - для характеристики современного состояния предприятий и определения тенденций развития сферы гостеприимства; структурно-логического анализа - для установления взаимосвязей между категориями исследуемой проблемы. Методологическим ориентиром исследования проблемы стали ключевые методологические подходы - аксиологический, системный, культурологический, компетентностный, синергетический и др. Научная новизна. Развит научный подход к определению структурно-содержательного наполнения механизма функционирования и развития аксиосферы систем клиентского сервиса за счет расширения субъектного состава, что придает системе эффрективного значения. Выводы. Обоснована целесообразность использования определенного набора формализованных подходов к формированию систем организационной культуры и профессионального компетентностного потенциала в системах клиентского сервиса, что, как следствие, 
обеспечит добавленную и рыночную стоимость бизнеса предприятий гостиничноресторанной сферы. Недостаточность комплексности и системности в освещении вопросов совершенствования и эффективности систем клиентского сервиса обусловливает потребность в дальнейших теоретических исследованиях этой проблемы.

- Ключевые слова: ценность; аксиология; аксиосфера; клиентский сервис; организационная (корпоративная) культура; профессиональная компетенция; гостиничноресторанный бизнес; сфера гостеприимства 